\title{
Ricardo Palma y Túpac Amaru
}

\author{
Por José Luis Ayala
}


Cronista, poeta, ensayista y narrador. Estudió en la Universidad Nacional Mayor de San Marcos y en la Ecole Practique des Hautes Studies de París. 
Las referencias históricas así como los datos fidedignos son notables en las Tradiciones de Ricardo Palma. Si se trata de comparar los hechos que narra con los que ahora se conocen, debido a la contribución de las ciencias sociales y de las nuevas fuentes de investigación, se puede afirmar que escribió luego de haber leído varios documentos. ¿Cómo es que Palma pudo narrar los inicios de la gran rebelión de José Gabriel Túpac Amaru? Sin duda, en base a la documentación que leyó como bibliotecario $^{1}$, pero muchos libros, periódicos y manuscritos de esa época se quemaron en el incendio de la Biblioteca Nacional $^{2}$, ocurrido en la madrugada del domingo 10 de mayo $1943^{3}$.

l El presidente Miguel Iglesias convenció en 1833 a Ricardo Palma para que se hiciera cargo de la dirección de la Biblioteca Nacional. El recinto estaba en ruinas a consecuencia de la guerra, invasión, ocupación y saqueo de parte de las tropas chilenas. En marzo de 1881, Palma, que trabajaba como subdirector, publicó una carta de protesta junto el director Manuel de Odriozola. El contralmirante Patricio Lynch, comandante en jefe del ejército de ocupación, ordenó la prisión de Palma en la Biblioteca y luego en un buque chileno. Estuvo doce días preso pero recuperó su libertad. Odriozola se asiló en la legación norteamericana. Se le llamó el "Bibliotecario mendigo" por el hecho de solicitar donaciones de libros. Palma como patriarca de las letras peruanas se retiró en marzo de 1912 a vivir a Miraflores, donde pasó los últimos años de su existencia.

2 El general José de San Martín, el 8 de agosto de 1821, fundó la Biblioteca Nacional del Perú, debido a la iniciativa del Ministro de Guerra y de Gobierno, Dr. Bernardo de Monteagudo. El Decreto de Creación de la Biblioteca Nacional inmediatamente concitó el interés de docentes e intelectuales. San Martín donó más de 700 libros de su biblioteca, Bernardo Monteagudo obsequió su biblioteca personal pero sobre todo los "Comentarios Reales" del Inca Garcilaso de la Vega.

3 Nunca se supo fehacientemente cómo es que en la madrugada del domingo 10 de mayo de 1943 se produjo un pavoroso incendio en la Biblioteca Nacional. Se dijo que fue producto de un corto circuito. Ese hecho fue calificado por los medios y escritores como "catástrofe nacional en el mundo intelectual". El ingrato acontecimiento produjo no solo una conmoción nacional, sino 
La bibliografía sobre Túpac Amaru hoy no solo es abundante sino que tan importante personaje fue históricamente reivindicado por el gobierno de Juan Velasco Alvarado. Desde entonces significa el punto de partida para un necesario proceso de descolonización ideológica, sin la cual será difícil pensar el Perú de los siglos venideros. Solo así Túpac Amaru también podrá ocupar el lugar que le corresponde en la memoria social $\mathrm{y}$, convertirse en una referencia fundamental para llevar a la práctica un nuevo sistema político. Palma con razón afirma: "No es del caso historiar aquí esta tremenda revolución que, como es sabido, puso en grave peligro al gobierno colonial. Poquísimo faltó para que entonces hubiese quedado realizada la obra de la Independencia”.

En efecto, en la tradición titulada "El corregidor de Tinta"4 Ricardo Palma empieza narrando: "Era el 4 de noviembre de 1780, el cura de Tungasuca, para celebrar su santo patrón, que lo era también de su majestad Carlos III ${ }^{5}$, tenía congregados en opíparo almuerzo a los más notables vecinos de la parroquia y algunos amigos de los pueblos inmediatos, que desde el amanecer habían llegado a felicitarlo por su cumpleaños".

que repercutió en el ámbito latinoamericano. Lamentablemente se perdió un valioso fondo documentario así como material bibliográfico, cultural y artístico. Según la información más confiable, se quemaron más de 100 mil volúmenes empastados y 40 mil manuscritos, además de irreemplazables piezas de colección. Desaparecieron, en medio del fuego, las salas de lectura "América", "Europa" y "Periódicos Peruanos". Pero se pudo reconstruir debido al interés, esfuerzo y trabajo del historiador Jorge Basadre, de acuerdo a un plan técnico. Basadre fundó la Escuela Nacional de Bibliotecarios para formar a personas especialistas en catalogación y conservación de libros. Publicó el "Boletín de la BNP". Las donaciones que recibió llegaron a la cifra de 134 mil volúmenes.

4 Ricardo Palma. El corregidor de Tinta. Tradiciones peruanas. Editorial Universo, 1987, Lima, Págs. 34-36.

5 Carlos III de Borbón. (Madrid, 20/01/1716 - 1/12/1788. Duque de Parma como Carlos I entre 1731 y 1735, rey de Nápoles como Carlos VII y rey de Sicilia como Carlos $V$ de 1734 a 1759 . Rey de España desde 1759 hasta su muerte. 
El cura Carlos Rodríguez tuvo el cuidado que el corregidor Antonio de Arriaga, estuviera presente y acompañado por el histórico cacique de Surimana, Pampamarca y Tungasuca José Gabriel Túpac Amaru II.

Palma describe con acierto magistral al corregidor Arriaga así: "Grosero en sus palabras, brusco de modales, cruel para con los indios de la mita y avaro hasta el extremo de que si en vez de nacer hombre hubiera nacido reloj, por no dar, no habría dado ni las horas, tal era su señoría. Y para colmo de desprestigio, el provisor y canónigos del Cuzco lo habían excomulgado solemnemente por ciertos ataques contra la autoridad eclesiástica". Sin embargo, la conversación giró en relación al carácter y anécdotas que el cura contó acerca del soberano de España.

Terminado el almuerzo, Arriaga comentó que la sentencia de excomunión recaída en su persona no lo hacía menos cristiano y que se trataba de un exceso de celo de parte de "esos canónigos barrigudos y abarraganados". Luego Túpac Amaru ofreció acompañarlo pero el corregidor respondió que no era necesario porque estaba muy apurado debido a obligaciones que debía cumplir en Tinta. Entonces todos se despidieron, salieron al patio y cada quien montó su caballo.

Después se supo que la rebelión de Túpac Amaru debió estallar varios meses antes. En el juicio que le siguió José Antonio de Areche se llegó a saber que las acciones se habían retrasado debido a que no se contaba con las armas necesarias, ni había llegado la ayuda que esperaba. Entonces, se conocieron también las cartas de Miguel de Montiel, ${ }^{6}$ quien desde Lima le

6 Miguel de Montiel. Cuando Túpac Amaru viajó a Lima para pedir el título de Inca y protestar por la pobreza de los peruanos, teniendo como mediador a 
preguntaba constantemente a Túpac Amaru, cuándo empezaría "la obra".

"A las seis de la tarde - dice Palma-, el insolente hidalgo galopaba en dirección a la villa de su residencia, cuando fue enlazado su caballo, y don Antonio se encontró en medio de cinco hombres armados, en los que reconoció a otros tantos de los comensales del cura.

- Dése preso vuesa merced -le dijo- Túpac Amaru, que era el que acaudillaba el grupo.

Y sin dar tiempo al maltrecho corregidor para que opusiera la menor resistencia, le remacharon un par de grillos y lo condujeron a Tungasuca.

Inmediatamente salieron indios con pliegos para el Alto Perú y otros lugares, y Túpac Amaru alzó bandera contra España”.

Apresado el corregidor fue maniatado y conducido fuertemente vigilado para ser procesado y condenado a la pena de muerte, acción que marcaría el inicio de una rebelión que conmovió los cimientos de la Colonia. Túpac Amaru mandó llamar a todos los habitantes para que presenciaran el ahorcamiento de un puka kumka (cuello rojo en quechua), pero sobre todo al representante del poder colonial y del rey de España.

Palma dice enseguida: "El 10 de noviembre destacábase una

Miguel de Montiel, se convenció de que nada obtendría por los medios legales. Miguel de Montiel posteriormente fue apresado en Lima y no negó conocer a Túpac Amaru desde cinco años atrás. Los españoles no entendieron por qué Túpac Amaru reclamaba el título de Inca, pues para ellos no tenía sentido. Le contestaron que debía dirigirse al rey de España, respuesta que fue suficiente para iniciar la rebelión de 1780 . 
horca frente a la capilla de Tungasuca, y al altivo español, vestido de uniforme y hoja landas: hopalanda, según Corominas, 'vestidura talar larga y pomposa'. Acompañado de un sacerdote que lo exhortaba a morir cristianamente, oyó del pregonero estas palabras: 'Esta es la justicia que don José Gabriel I, por la gracia de Dios, Inca, rey del Perú, Santa Fe, Quito, Chile, Buenos Aires y continente de los mares del Sur, duque y señor de los Amazonas y del gran Paititi, manda hacer en la persona de Antonio Arriaga por tirano, alevoso, enemigo de Dios y sus ministros, corruptor y falsario".

Desde muy temprano llegaron hombres y mujeres quechuas para presenciar un acto jamás visto antes. El corregidor Arriaga confesó, imploró que se le perdonara, se arrodilló, lloró y no quiso salir del calabozo, pero a rastras lo subieron al cadalso. El verdugo le arrancó el traje de militar español para degradarlo, le puso una túnica larga y enfundó en la cabeza una capucha negra. Pero sucedió que la soga que lo elevaba del suelo, se arrancó. Entonces Arriaga ante la sorpresa de la muchedumbre empezó a correr con dirección al templo gritando:

“iSalvo soy! iLa iglesia me llamó! iLa iglesia me vale!

Iba ya el hidalgo a penetrar el sagrado, cuando se le interpuso el Inca Túpac Amaru, lo tomó del cuello, diciéndole:

- iNo vale la iglesia a tan gran pícaro como vos! iNo vale la iglesia a un excomulgado por la Iglesia!".

En medio de una atmósfera cargada por una rebelión que empezaba a incendiar todos los pueblos, caseríos y caminos, llegó al Cuzco la alarmante noticia de la rebelión de Túpac Amaru II. De inmediato los realistas organizaron un ejército de 2000 soldados quechuas al mando del corregidor español 
de Quispicanchis Fernando de Cabrera. El día 14 de noviembre la tropa realista se dirigió hacia el sur confiando en una fácil victoria. Desconocía que Túpac Amaru había preparado un ejército de campesinos con pocas armas pero compuesto de 6000 hombres con hondas y palos.

En la mañana del día 17 de noviembre, cuando Cabrera se encontraba en inmediaciones del pueblo de Urcos, le entregaron una orden de la Junta de Guerra del Cuzco, debía detenerse y esperar a los refuerzos que estaban en camino. Pero el corregidor no hizo caso y avanzó a toda marcha para llegar ese mismo día a Sangarará. Como arribó de noche, los soldados realistas acamparon en la plaza, pero luego se enteraron que se aproximaban las fuerzas tupacamaristas. Entonces. Cabrera ordenó atrincherarse en el templo así como en los arcos de adobe para resistir mientras llegaran los refuerzos.

Sin embargo, antes que amaneciera, en la madrugada del 18 de noviembre de 1780, una muchedumbre de quechuas partidarios de Túpac Amaru II, sorpresivamente rodeó la plaza de Sangarará. José Gabriel habló en voz alta y juró respetar la vida de los realistas si entregaban las armas y se rendían. Cabrera se negó llegar a un entendimiento sin prever las consecuencias. Algunos mestizos intentaron escapar del templo, pero fueron acribillados por orden del corregidor.

Cuando el sol asomó por las cumbres de Sangarará, Túpac Amaru ordenó atacar y dar comienzo a lo que fue una terrible batalla. Miles de piedras y fuego de fusilería cayeron entre las filas de ambos ejércitos. Los realistas sitiados comprendieron que no resistirían el empuje de quechuas diestros en el manejo de hondas. A fin de salir de la capilla alguien ordenó disparar un cañonazo para abrir un forado y así saliera la gente. Pero el fuego alcanzó a un polvorín y así empezó un incendio dantesco. 
Se desplomó el techo, luego una pared y mucha gente empezó a morir asfixiada, pisoteada en medio de una gran confusión y pánico. El fuego se propagó debido a los vestidos de tela de las efigies, adornos de cartón de los altares y retablos.

Muchos soldados realistas heridos y cayeron muertos, entre ellos el corregidor Cabrera, el gobernador Tiburcio Landa y el cacique Pedro Sawarawra. En cambio, en las filas tupacamaristas murieron veinte honderos jóvenes. Túpac Amaru respetó la vida de los prisioneros y sobrevivientes, pagó a los curas los entierros, curó los heridos y reconstruyó el templo. Pero fue acusado de haber profanado, incendiado, saqueado y destruido la capilla por lo que fue excomulgado.

Durante la Colonia, un arma letal y recurso psicológico eficaz fue la excomunión, pregonada por los curas desde los púlpitos. Es decir, la determinación de una muerte civil, desprecio, censura y exclusión social de personas indefensas, usando todo el poder de la Iglesia colonial así como el sistema de control del subconsciente colectivo.

La excomunión era un público castigo moral y a veces abierta expulsión de una persona para convertirla en fantasma, en una sombra doliente y despreciable. Podía ser permanente o temporal. Durante el tiempo de la excomunión, la persona excomulgada podía seguir perteneciendo a la comunidad, pero debía cumplir una sentencia; la palabra proviene del latín $e x$ communicatio. En algunos casos podía perder el derecho de entrar a un templo o capilla, como también ser partícipe de actos religiosos. La excomunión se refería muchas veces a la exclusión de la Eucaristía. Esta, ahora, inusual práctica se remonta al Concilio de Elvira, en el año 306. En fin, se trataba de una pena impuesta por la legislación canónica, de modo que un católico era vergonzosamente excluido de la práctica religiosa. 
Usando razones jurídicas eclesiásticas, el método de la persecución y muerte civil, el purpurado obispo del Cuzco, Juan Manuel Moscoso y Peralta, a pesar de haberse resistido durante varios días, se vio en la obligación de excomulgar a José Gabriel mediante un documento que se llamó Cedulón de excomunión, que consistía en un texto pegado en el frontis de los templos y capillas para que los feligreses lo leyeran y cumpliera la sentencia eclesiástica.

El 17 de noviembre, el obispo primero leyó el cedulón en la misa de las ocho de la mañana y luego dispuso se conociera su contenido: "Tengan por público excomulgado, de excomunión mayor a José Túpac Amaru, cacique del pueblo de Tungasuca, por incendiario de las capillas públicas y de la iglesia de Sangarará, por grasador de los caminos, por rebelde traidor al Rey, Nuestro Señor. Por revoltoso, por perturbador de la paz y usurpador de los Reales Derechos; y a todos cuanto le dan auxilio, favor y fomento y a los que le acompañan, si luego que tuvieran noticia de esta censura no se separasen de su comunicación, y se desisten de auxiliarlo su depravado intento; y bajo la misma pena, ninguno se atreva a desfijar este cedulón del lugar de la iglesia donde se fijare, reservando a Nos la absolución de todo, que es hecho en la ciudad del Cuzco. Juan Manuel, Obispo del Cuzco. Por mandato de su Señoría Ilustrísima, el Obispo mi Señor. Doctor José Domingo de Frías, secretario"7.

Después del degollamiento de Túpac Amaruy posterior asesinato de Pedro Vilca Apasa y Túpac Catari, las autoridades españolas realizaron una horrenda carnicería y tomaron represalias contra todos los parientes de Túpac Amaru. Hasta que José Antonio de

7 Colección Documental de la Independencia del Perú. Tomo II. La Rebelión de Túpac Amaru. Volumen $2^{\circ}$ La Rebelión. Comisión Nacional del Sesquicentenario de la Independencia del Perú, págs. 271-272. Talleres Gráficos “Cecil”, 1971, Lima. 
Areche, finalmente logró que se comprendiera al obispo en un proceso de investigación bajo la sospecha de conocer los planes de Túpac Amaru y no haberlo denunciado. Es cierto que Juan Manuel Moscoso y Peralta, en un principio estuvo de acuerdo en lograr el cambio de autoridades abusivas y corruptas. Pero habiendo pasado José Gabriel de las palabras a los hechos, se vio seriamente comprometido y más aun con el testimonio en su contra de parte de un cura de su extrema confianza, quien conocía todas sus acciones. Fue el sacerdote Jiménez de Villalba quien delató al obispo ante el terrible José Antonio de Areche.

“Jamás imaginó el obispo que después sería llamado a Lima en 1784, para exponer y defender prácticamente su conducta primero de apoyo a Túpac Amaru y, luego, de colaboración a regañadientes cuando se le pidió excomulgar a 'un enemigo de España'. Al no convencer durante el juicio a que fue sometido en Lima, los juzgadores creyeron conveniente que su caso pasara a un tribunal de España, por lo que el 5 de abril de 1786 se embarcó con destino a Madrid y allí logró convencer a sus juzgadores respecto a su inocencia y fue rehabilitado, con la condición de que no volviera a América y menos al Cuzco, habiendo sido nombrado después arzobispo de Granada el 3 de agosto de 1789 y además se le concedió en 1794 la Gran Cruz de la Orden de Carlos III. ¿Cómo no iba a conseguir eso y mucho más si el purpurado era un hombre dueño de una gran fortuna? Obsequió una magnífica custodia de la catedral de Granada con abundante pedrería fina con un costo de 80,000 pesos, luego cuando España enfrentó una seria crisis económica frente a la guerra con Francia, obsequió la cantidad de 200,000 reales de sus arcas, más la renta del arzobispado referente a sus pensiones"8.

8 José Luis Ayala. José Fermín de Sata y Bussy. Guerrero de la poesía y la esperanza. Inédito. 
Después de la derrota de José Gabriel en la batalla de Tinta, tal como escribe Ricardo Palma: "El 6 de abril, Viernes de Dolores del año 1781, cayeron prisioneros el Inca y sus principales vasallos, con los que se ejercieron los más bárbaros horrores. Hubo lenguas y manos cortadas, cuerpos descuartizados, horca y garrote vil. Areche autorizó barbaridad y media”.

Con el suplicio del Inca, de su esposa doña Micaela, de sus hijos y hermanos, quedaron los revolucionarios sin un centro de unidad. Sin embargo, la chispa no se extinguió hasta julio de 1783, en que tuvo lugar en Lima la ejecución de don Felipe Túpac, hermano del infortunado Inca, caudillo de los naturales de Huarochirí. "Así -dice Dean Funes- terminó esta revolución y difícilmente presentará la historia otra ni más justificada ni menos feliz".

Sin embargo, es preciso hacer algunas precisiones: "José Gabriel Túpac Amaru y Micaela Bastidas tuvieron tres hijos varones. El mayor, Hipólito, fue asesinado en el cadalso, Mariano y Fernando fueron desterrados a perpetuidad. Durante la travesía a España murió Mariano. Juan Bautista, hermano de José Gabriel, también fue desterrado junto con los familiares de Túpac Amaru. Así se cumplió la siniestra orden de borrarlos del la faz del mundo.

Fernando, un niño de diez años, fue obligado a mirar el degollamiento de su padre, la muerte a patadas de su madre y la de su hermano Hipólito. Luego sería aislado en el Cuzco y enseguida caminó encadenado hasta Lima para sufrir un encierro en el castillo del Real Felipe. Después de dos años recién llegó la orden de prisión hasta su muerte en una cárcel del África. Las autoridades españolas embarcaron hacia España a 29 prisioneros familiares de José Gabriel. 
En la travesía murieron 18 pasajeros, Mariano murió el 27 de julio de 1784 a los 21 años, frente a las costas de Brasil. Luego de un penoso viaje de diez meses, el navío llegó a Cádiz a comienzos de febrero en 1785. El virrey Jáuregui sugirió que no fueran enviados al África sino a un lugar de España por temor a que alguna potencia enemiga los rescatara. Los presos fueron destinados a las mazmorras de San Sebastián y Santa Catalina (Cádiz). Fernando se entregó a las autoridades españolas después que naufragó, en Peniche, el navío "San Pedro de Alcántara" que lo llevaba a España.

Desde la prisión, cuando cumplió 16 años le escribió al rey Carlos III en 1787 pidiendo su excarcelación. Padeció un dilatado cautiverio lleno de enfermedades y miseria. Hasta que en 1788 se produjo la orden para que los prisioneros fueran trasladados a diversas provincias. Fernando Túpac Amaru, único hijo sobreviviente de José Gabriel, fue internado en las Escuela Pías de Getafe. A su tío Juan Bautista lo enviaron a Ceuta y a Miguel Bastidas junto a su mujer e hija a Zaragoza. Fernando falleció en Madrid, el 19 de agosto de 1798" .

El hermano menor de José Gabriel llamado Juan Bautista Túpac Amaru Monjarrás, nació en Tungasuca en 1747. Fue hijo del cacique Miguel Túpac Amaru y su madre se llamó Ventura Monjarrás. Se casó con Susana Guerra y se dedicó como toda su familia a la ganadería, agricultura, comercio y arrieraje. Acompañó a su hermano José Gabriel en la rebelión contra la opresión española. Detenido en el Cuzco, permaneció preso hasta el 22 de noviembre de 1783; luego fue enviado a las mazmorras del Real Felipe del Callao. Después desterrado a perpetuidad a España junto con todos sus parientes prisioneros.

9 José Luis Ayala. Diario La Primera. Fernando Túpac Amaru. 23 de setiembre, Lima, 2010. 
Permaneció tres años preso en el Castillo San Sebastián (Cádiz), luego pasó al presidio de Ceuta, un enclave español en el norte de África, donde estuvo preso por 35 años. Conoció a revolucionarios americanos condenados por sus ideas independentistas, por ejemplo a Marcos Duran Martel y a Juan Bautista Azopardo. Duran lo ayudó para que viajara a Buenos Aires; allí, por orden del gobierno, se le asignó una pensión para que escribiera sus Memorias con el título: "El dilatado cautiverio bajo el gobierno español de Juan Bautista Túpac Amaru, $5^{\circ}$ nieto del último emperador del Perú"10.

En el histórico Congreso de Tucumán de 1816, que declaró la Independencia de Argentina, Manuel Belgrano propuso su nombre como candidato para el trono de América, las Provincias Unidas en Sudamérica. Pero Belgrano fue derrotado por la burguesía mercantil de Buenos Aires. Juan Bautista finalmente murió en Buenos Aires el 2 de septiembre de 1827; está sepultado en una tumba del cementerio de la Recoleta de Buenos Aires. El mausoleo está situado cerca al de la familia Duarte, donde está sepultada María Eva o Evita Perón.

Ahora sabemos más en referencia a José Gabriel Túpac Amaru, debido a Boleslao Lewin, Carlos Daniel Valcárcel, Jhon Fisher, Jorge Cornejo Buroncle, Juan José Vega, Jhon Rowe, Emilio Choy, Oscar Comblit, Jan Szeminski, Lorenzo Huertas, Alberto Flores Galindo, Augusto Ramos Zambrano, entre otros notables investigadores. Pero sobre todo a la Colección Documental de la Independencia del Perú. La Rebelión de Túpac Amaru. Editada en 1971 por la Comisión Nacional del Sesquicentenario de la Independencia del Perú. Así es como se tiene acceso a

10 José Luis Ayala. Cronivela. Juan Bautista Túpac Amaru. El dilatado cautiverio bajo el gobierno español de Juan Bautista Túpac Amaru, $5^{\circ}$ nieto del último emperador del Perú. Fondo Editorial Cultura Peruana. Lima, 2013. Págs. 180-219. 
una frondosa información documentaria. En el caso de Juan Bautista Túpac Amaru el aporte del escritor argentino Eduardo Astesano $^{11}$ ha sido fundamental.

Al no haber triunfado Túpac Amaru y al haber dejado un sentimiento de derrota que pesa mucho en el imaginario de los peruanos, Emilio Choy ha dicho: "En la historia del Perú, las fuerzas que tratan de introducir mejoras o cambios en la estructura de nuestra sociedad, parece que son inevitablemente derrotadas por una o más veces antes de lograr su victoria. Los borbones pretendieron mejorar la penetración hacia la selva a través de las misiones franciscanas - progresista para su tiempo-, pero fueron vencidas por un sistema de guerra prolongada, bajo las inspiración de los hijos de Loyola, y llevada a la práctica por Juan Santos Atahualpa, en 1742-56; pero no siempre las guerras que se proclaman independentistas tienen un contenido de avanzada, aunque en lo formal de este caso permitieron deducir que se podía vencer al poderío español aun sin ayuda exterior"12.

Pero ahora, con ocasión del Bicentenario de la Independencia Nacional, lo menos que debería hacer el Estado Peruano es repatriar los restos de Fernandito Túpac Amaru, así como los de Juan Bautista Túpac Amaru y recibirlos con honores de jefe de Estado, y sobre todo reunir simbólicamente los restos dispersos de José Gabriel Túpac Amaru II, de Micaela Bastidas y de todos los precursores, y edificar en homenaje a ellos un monumento de mármol en la plaza de Armas del Cuzco. De esa manera en algo podría repararse el inmenso dolor colectivo

11 Eduardo Astesano. Juan Bautista de América. El rey inca de Manuel Belgrano. Tiempo de América. Ediciones Castañeda. Buenos Aires. 1979.

12 Emilio Choy. Contradicciones y trascendencia de la revolución. Túpac Amaru. Antología de Alberto Flores Galindo. Págs. 266-268. Retablo de papel ediciones. Lima, 1976. 
y frustración que sentimos los peruanos de buena fe, pese al tiempo transcurrido.

Ricardo Palma dijo que de haber triunfado José Gabriel Túpac Amaru II, hubiera logrado la Independencia del Perú. Esa es una valiosa contribución histórica del tradicionalista para la reeducación de la memoria y desestructuración de las ideas dominantes con las que se han formado muchas generaciones, con una mentalidad derrotista y baja estima colectiva. A los 200 años de creación y crisis de la República, hispano, criolla, Túpac Amaru de todos modos regresará como dice el poeta Alejandro Romualdo: "Gritando iLibertad! sobre la tierra/ ha de volver. iY no podrán matarlo!". 